\title{
Gabrielle HOUBRE, Histoire des mères et filles, Paris, Éditions de La Martinière, 2006, 223 p.
}

Yvonne Knibiehler

\section{(2) OpenEdition}

12 Journals

Édition électronique

URL : https://journals.openedition.org/clio/5172

DOI : $10.4000 /$ clio. 5172

ISSN : 1777-5299

Éditeur

Belin

Édition imprimée

Date de publication : 1 avril 2007

Pagination : 249-290

ISBN : 978-2-85816-900-9

ISSN : 1252-7017

Référence électronique

Yvonne Knibiehler, «Gabrielle HOUBRE, Histoire des mères et filles, Paris, Éditions de La Martinière, 2006, 223 p. », Clio. Histoire, femmes et sociétés [En ligne], 25 | 2007, mis en ligne le 03 octobre 2007 consulté le 25 avril 2022. URL : http://journals.openedition.org/clio/5172 ; DOI : https://doi.org/ $10.4000 /$ clio. 5172

Ce document a été généré automatiquement le 25 avril 2022.

Tous droits réservés 


\title{
Gabrielle HOUBRE, Histoire des mères et filles, Paris, Éditions de La Martinière, 2006, 223 p.
}

\author{
Yvonne Knibiehler
}

1 Les Éditions de La Martinière publient aujourd'hui de «beaux livres » sur des thèmes délaissés depuis les années 1970 : la famille, la maternité1. Et elles tiennent compte des recherches récentes en sciences humaines, alors que jusqu'à présent, dans ce genre de publications, les images supplantaient le texte, l'éditeur privilégiant l'émotion esthétique de l'acheteur². L'histoire des mères et filles affirme le très vif intérêt de cette initiative.

2 L'illustration est magnifique. Les images, bien choisies, bien reproduites, bien présentées, retiennent d'autant mieux l'attention qu'elles sont souvent inattendues. Sur ce sujet, on croit tout connaître. Or, à l'exception de l'inévitable madame VigéeLebrun, on va de découvertes en découvertes. L'auteur fait preuve d'une culture impressionnante en matière d'iconographie. Il est vrai que c'est un de ses domaines favoris de recherche.

3 Cette impression de découverte tient au fait que, loin de s'en tenir aux corpus hexagonaux, Gabrielle Houbre présente de nombreuses œuvres étrangères, peu connues en France. Mondialisation oblige. Sur 115 reproductions, plus d'une trentaine proviennent de collections anglaises, américaines, allemandes, hollandaises, italiennes, espagnoles. Autre diversification stimulante : à côté des tableaux et dessins de maîtres, qui donnent de la relation mère-fille une représentation socialement valorisée, des productions plus modestes (dira-t-on plus populaires?) tiennent une place substantielle et portent d'autres messages. Ainsi une trentaine de gravures et de lithographies sont empruntées à la presse illustrée: livres de contes, périodiques, journaux satiriques. Ces images, au lieu d'idéaliser, installent souvent une vision dérangeante. On y voit des mères (ou marâtres) brutales, fouettant les petits, des mères jalouses de leur fille, des mères maquerelles qui vendent les charmes de leur 
progéniture. Enfin une quinzaine de photographies montrent cette technique pénétrant peu à peu l'intimité familiale.

Chacune de ces illustrations est commentée en marge, soit par une brève notice concernant son auteur, soit, en cas d'anonymat, par une mise en contexte de la scène évoquée. Les images contribuent-elles à une meilleure intelligence du sujet traité ? Oui, sans aucun doute. La sensibilité personnelle des artistes, même étroitement conditionnée par la culture dominante, va souvent au-delà de tous les discours : elle touche plus directement, elle traduit l'indicible, elle dévoile le non-dit.

La distribution de cette superbe documentation peut surprendre. Certaines images sont rassemblées en «cahiers thématiques " à peine lestés d'un commentaire très succinct. Les autres accompagnent le propos savant, lequel est divisé en six chapitres, chaque chapitre s'achevant par un petit recueil de citations (autre manière d'illustrer). Les "cahiers thématiques" semblent destinés à masquer un décalage entre le titre de l'ouvrage et son contenu réel. Le choix du titre - prérogative de l'éditeur - : Histoire des mères et filles, est manifestement abusif, car le texte et les images ne portent que sur les deux derniers siècles. L'éditeur a-t-il voulu suivre le sillage de l'ouvrage récent de Caroline Eliacheff et Nathalie Heinich, Mères-filles. Une relation à trois (Albin Michel, 2002) ? L'intention serait louable dans la mesure où elle peut donner aux historien(ne)s l'opportunité de nuancer les enseignements des psychologues et des sociologues, lesquels croient pouvoir énoncer des vérités éternelles et universelles, alors qu'ils observent essentiellement le présent. L'histoire a beaucoup à leur apprendre. Encore faut-il ne pas tricher avec elle.

Gabrielle Houbre ne triche pas. Universitaire scrupuleuse, elle ne traite que la période qu'elle connaît bien, des Lumières à la Libération. À aucun moment elle ne prétend écrire toute l'histoire des mères et filles. Pourtant, les deux premiers cahiers thématiques intitulés «Figures mythiques » et "Contes... », font semblant d'explorer le passé lointain. En réalité, les oeuvres qu'ils montrent datent du XIXe siècle : elles disent comment des artistes se représentaient alors Salomé, Clytemnestre, Blanche-Neige, Peau d'Âne. Ces peintres - tous du sexe fort - redoutent visiblement l'emprise de la mère. La même inquiétude, Gabrielle Houbre le souligne, transparaît alors à travers de nombreuses oeuvres littéraires et musicales. De ce fait, dans l'ensemble du livre, sur 115 oeuvres, 75 sont signées par des hommes. Une vingtaine ne sont pas attribuées, mais on sait que les femmes étaient rares dans ces métiers. Autant dire que l'ouvrage donne à voir essentiellement des interprétations masculines datées. Ces artistes masculins approuvent et justifient les normes officielles qui encadrent alors la relation mère-fille. Ne sous-estimons pas pour autant la richesse de leurs intuitions. Théodore Roussel, par exemple, lorsqu'il montre une «Jeune fille lisant », suggère les voies et les moyens de l'émancipation des filles. Il faut d'ailleurs reconnaître que les quelques images produites par des femmes ne présentent pas d'originalité significative. Les femmes artistes avaient beaucoup de peine à se faire reconnaître ; plus encore que les hommes, elles restaient soumises aux modèles agréés par la société.

7 Le texte se développe en grandes pages denses. Même s'il escorte parfaitement les images, il ne leur est pas asservi, il peut être lu pour lui-même. Abondamment documenté, nourri des recherches les plus récentes, il constitue un bilan remarquable de ce que l'on sait à présent sur la relation mère-fille depuis les Lumières. Solidement construits, les six chapitres suivent un parcours biographique, de la naissance de l'enfant fille jusqu'à la mort de la mère. Cette organisation, qui n'est pas vraiment 
nouvelle ${ }^{3}$, a le mérite d'élargir le champ de la maternité, trop souvent réduite au maternage et à l'éducation virginale. Ici on saisit le moment fort du mariage, on assiste à l'émergence de la belle-mère et de la grand-mère, on discerne la portée du deuil. Toutefois, si la perspective biographique se révèle efficace, elle n'est pas dépourvue d'inconvénients. Notamment, elle élucide mal les facteurs historiques du changement. L'auteur analyse avec perspicacité un certain modèle éducatif, mais elle ne montre pas bien les raisons de son avènement, ni celles de son dépérissement.

8 L'accent est mis sur l'importance donnée alors à l'éducation maternelle. Ici l'historienne apporte au discours "psy " un complément indispensable. La relation mère-fille n'est pas seulement une relation à deux, ni à trois. Inscrite dans tout un ensemble, elle traduit un projet de société. Les gens du XIXe siècle ont rêvé de protéger la vie privée en la confiant aux femmes, pendant que les hommes affrontaient de violents bouleversements économiques et politiques. Cette intention collective a mûri un modèle éducatif très élaboré, qui à la fois glorifie et subordonne le deuxième sexe.

Ce modèle devait-il forcément produire des oies blanches? Gabrielle Houbre passe un peu vite sur cet avatar si important. Surgit là, en effet, un problème capital, celui de l'éducation sexuelle, qui auparavant n'avait jamais été identifiée comme telle. À la campagne, où l'on voyait les bêtes s'accoupler et mettre bas, les filles s'informaient entre elles, des aînées aux cadettes, ou grâce à des domestiques, sans que la mère intervienne. Dès lors que l'éducation de la fille est censée relever essentiellement de sa mère, celle-ci endosse une responsabilité inédite, sans recevoir les moyens de l'assumer. En effet, la culture savante commence à supplanter la culture empirique : Diderot, lorsqu'il veut instruire sa fille sur le sexe et la reproduction recourt sans hésiter aux planches anatomiques. Mais les femmes, les mères sont laissées délibérément à l'écart de la culture savante, réservée aux hommes. Une autre considération leur impose silence : selon l'esprit du code Napoléon, il appartient au mari, à lui seul, d'initier à son gré son épouse, qui lui doit obéissance. Quoi qu'il en soit, le problème de l'éducation sexuelle reste encore aujourd'hui bien difficile à résoudre.

Gabrielle Houbre a éclairé, avec beaucoup de savoir et de talent, L'histoire des mères et filles à une époque particulièrement attachante parce qu'elle est toute proche, et nous n'en sommes pas encore totalement détachés. Il serait possible, désormais, de prendre davantage de recul et de considérer L'histoire des mères et filles dans la longue durée 4 . Je propose ici quelques aperçus. Pour en comprendre l'enchaînement, il faut admettre qu'une grande différence existe entre la relation pèrefils et la relation mère-fille. Dans les deux cas, il s'agit de transmettre une identité sexuée. Mais pour les hommes c'est plus simple : de père à fils, la transmission ne met en jeu que leurs ego respectifs. De mère à fille, la transmission met en jeu la vocation même de l'espèce humaine. Nous sommes des mammifères, mais nous ne pouvons plus vivre simplement notre animalité, nous sommes condamnés à la culture. Ce qui passe par les femmes, c'est le renouvellement - biologique et culturel - de l'espèce, soit l'essence de l'humain. Le mythe de Déméter l'indique déjà, à propos du sort de Coré / Perséphone. Rappelons que le culte des « deux déesses » a été le plus répandu et le plus durable, dans la culture hellénique ; et les Thesmophories, célébrées chaque année par les mères et les futures mères, les hommes étant exclus, revêtaient une signification symbolique très forte. À l'ère chrétienne, dès le XIIe siècle, le relais est pris par Sainte Anne, mère de trois filles, dont la Vierge Marie. La très riche iconographie qu'elle a inspirée témoigne sur l'évolution de la sensibilité chrétienne occidentale; elle culmine 
avec le chef-d'oeuvre de Léonard de Vinci ${ }^{5}$. Une première désacralisation devient perceptible vers la fin du XVIIe siècle : madame de Sévigné n'hésite pas à mettre au premier plan la tendresse humaine, dont l'Église se méfiait. Et Philaminte, protagoniste des Femmes savantes de Molière, presse ses filles d'accéder aux savoirs profanes. La philosophie des Lumières et la Révolution française inventent et imposent un reconditionnement moral et social, celui-là même que décrit Gabrielle Houbre. Ensuite, l'humanisme féministe, en sa deuxième vague, apporte aux femmes le pouvoir de ne plus enfanter. Quelles suites les filles et leurs mères voudront-elle, pourront-elles donner à ce dernier bouleversement?

\section{NOTES}

1. En septembre 2006, elles ont publié Une histoire de l'allaitement de MarieFrance Morel et Didier Lett.

2. Rappelons cependant que L'histoire des mères du Moyen Âge à nos jours (Montalba 1980, Hachette Pluriel 1982), que j'ai écrite en collaboration avec Catherine Fouquet, inaugurait cette démarche.

3. J'ai moi-même inauguré cette démarche dans La révolution maternelle (Perrin 1997), chapitres III et VI.

4. Dans le cadre de la Maison Méditerranéenne des Sciences de l'Homme, et de l'UMR. TELEMME, le Groupe de Recherches Femmes Méditerranée a organisé des séminaires et une journée d'études sur La puissance maternelle. Les communications seront publiées. Parmi elles, signalons : Viviane Pirenne-Delforge, « Maternité et divinité en Grèce antique. L'exemple de Déméter »; et Danièle Haase-Dubosc, « Rôle et perception des mères dans Les femmes savantes de Molière et dans la société française du XVIIe siècle ».

5. Estrella Ruiz-Calvez, « Religion de la Mère, religion des mères. Sainte Anne éducatrice. ", in Jean Delumeau, La religion de ma mère, les Éditions du cerf, Paris 1992. Dans ce même ouvrage, lire aussi : Marcel Bernos, « la catéchèse des filles par les femmes aux XVIIe et XVIIIe siècles ». 